\title{
The Use of FDG-PET to Target Tumors by Radiotherapy
}

Citation for published version (APA):

Lammering, G., De Ruysscher, D., van Baardwijk, A., Baumert, B. G., Borger, J., Lutgens, L., van den Ende, P., Ollers, M., \& Lambin, P. (2010). The Use of FDG-PET to Target Tumors by Radiotherapy. Strahlentherapie Und onkologie, 186(9), 471-481. https://doi.org/10.1007/s00066-010-2150-1

Document status and date:

Published: 01/09/2010

DOI:

10.1007/s00066-010-2150-1

Document Version:

Publisher's PDF, also known as Version of record

\section{Document license:}

Taverne

\section{Please check the document version of this publication:}

- A submitted manuscript is the version of the article upon submission and before peer-review. There can be important differences between the submitted version and the official published version of record.

People interested in the research are advised to contact the author for the final version of the publication, or visit the DOI to the publisher's website.

- The final author version and the galley proof are versions of the publication after peer review.

- The final published version features the final layout of the paper including the volume, issue and page numbers.

Link to publication

\footnotetext{
General rights rights.

- You may freely distribute the URL identifying the publication in the public portal. please follow below link for the End User Agreement:

www.umlib.nl/taverne-license

Take down policy

If you believe that this document breaches copyright please contact us at:

repository@maastrichtuniversity.nl

providing details and we will investigate your claim.
}

Copyright and moral rights for the publications made accessible in the public portal are retained by the authors and/or other copyright owners and it is a condition of accessing publications that users recognise and abide by the legal requirements associated with these

- Users may download and print one copy of any publication from the public portal for the purpose of private study or research.

- You may not further distribute the material or use it for any profit-making activity or commercial gain

If the publication is distributed under the terms of Article $25 \mathrm{fa}$ of the Dutch Copyright Act, indicated by the "Taverne" license above, 


\title{
The Use of FDG-PET to Target Tumors by Radiotherapy
}

\author{
Guido Lammering, Dirk De Ruysscher, Angela van Baardwijk, Brigitta G. Baumert, Jacques Borger, \\ Ludy Lutgens, Piet van den Ende, Michel Öllers, Philippe Lambin'1
}

\begin{abstract}
Fluorodeoxyglucose positron emission tomography (FDG-PET) plays an increasingly important role in radiotherapy, beyond staging and selection of patients. Especially for non-small cell lung cancer, FDG-PET has, in the majority of the patients, led to the safe decrease of radiotherapy volumes, enabling radiation dose escalation and, experimentally, redistribution of radiation doses within the tumor. In limited-disease small cell lung cancer, the role of FDG-PET is emerging. For primary brain tumors, PET based on amino acid tracers is currently the best choice, including high-grade glioma. This is especially true for low-grade gliomas, where most data are available for the use of ${ }^{11} \mathrm{C}-\mathrm{MET}$ (methionine) in radiation treatment planning. For esophageal cancer, the main advantage of FDG-PET is the detection of otherwise unrecognized lymph node metastases. In Hodgkin's disease, FDG-PET is essential for involved-node irradiation and leads to decreased irradiation volumes while also decreasing geographic miss. FDG-PET's major role in the treatment of cervical cancer with radiation lies in the detection of para-aortic nodes that can be encompassed in radiation fields. Besides for staging purposes, FDG-PET is not recommended for routine radiotherapy delineation purposes. It should be emphasized that using PET is only safe when adhering to strictly standardized protocols.
\end{abstract}

Key Words: PET · Radiotherapy · Treatment planning · Target delineation

Strahlenther Onkol 2010;186:471-81

DOI 10.1007/s00066-010-2150-1

\section{Der Einsatz der FDG-PET bei der Behandlung von Tumoren mittels Strahlentherapie}

Die Fluordesoxyglucose-Positronenemissionstomographie (FDG-PET) spielt eine zunehmende Bedeutung in der Strahlentherapie, neben der bereits etablierten Bedeutung für Tumorstaging und Patientenselektion. Insbesondere bei nichtkleinzelligen Lungenkarzinomen führt der Einsatz der FDG-PET in der Mehrzahl der Fälle zu einer unbedenklichen Abnahme des Strahlenvolumens, wodurch Dosiseskalationen und auf experimenteller Ebene selbst Dosisumverteilungen der Strahlendosis im Zielvolumen möglich werden. Bei kleinzelligen Lungenkarzinomen nimmt die Bedeutung der FDG-PET ebenfalls zu. Bei primären Hirntumoren stellt die Aminosäure-PET derzeit die beste Wahl dar, auch bei den hochgradigen Gliomen. Für die niedriggradigen Gliome favorisieren die meisten Daten den Einsatz von ${ }^{11}$ C-MET (Methionin) in der Strahlentherapieplanung. Beim Ösophaguskarzinom liegt der wesentliche Vorteil der FDG-PET in der Detektion von unerkannten Lymphknotenmetastasen. Beim Morbus Hodgkin ist die FDG-PET essentiell für die „involved-field“-Bestrahlung und führt zu einem reduzierten Strahlenvolumen bei gleichzeitig vermindertem Risko der geographischen Fehlbehandlung. Die bedeutendste Rolle der FDG-PET bei der Behandlung des Zervixkarzinoms liegt in der Detektion von paraaortalen Lymphknoten, die in das Bestrahlungsgebiet mit aufgenommen werden. Zusammenfassend wird die FDG-PET neben dem Einsatz beim primären Tumorstaging derzeit nicht für den Routineeinsatz bei der Einzeichnung des Zielvolumens in der Strahlentherapie empfohlen. Der Einsatz der FDG-PET sollte nur nach streng standardisierten Protokollen erfolgen.

Schlüsselwörter: PET · Strahlentherapie · Bestrahlungsplanung · Zielvolumeneinzeichnung

${ }^{1}$ MAASTRO Clinic, Radiation Oncology, Maastricht, The Netherlands. 


\section{Introduction}

Radiotherapy is a key treatment modality in the curative treatment of patients with cancer. The probability for radiotherapy to achieve tumor control is dependent on two crucial issues: dose and treatment time on the one hand and precise delivery of that dose on the tumor on the other. The latter seems obvious, but is not trivial at all. Indeed, theoretically, when extremely high radiation doses (e.g., $200 \mathrm{~Gy}$ ) could be given to the tumor only, thus sparing normal tissues, a virtually $100 \%$ probability to achieve local tumor control would emerge, without toxicity. Apart from biological and physical factors, central to achieve, the ultimate therapeutic ratio is adequate delineation of the tumor. An incorrect definition of the gross tumor volume (GTV, i.e., detectable tumor) or clinical target volume (CTV, tumor plus a margin for microscopic extension) is a source of systematic errors, which can lead to undertreatment and reduces the probability of tumor control.

Perfect delineation of the tumor requires - apart from optimal diagnostic accuracy (cancer or not) - also the capability to sharply identify the anatomic borders of the tumor. Indeed, underdosage of parts of the tumor results in a dramatic decrease in tumor control probability. Moreover, many tumors move substantially due to physiological processes such as respiration, cardiac beats, bowel and bladder filling. As the delivery of radiotherapy typically takes $10-15 \mathrm{~min}$, any imaging modality should take this time frame into account. Tracking or gating techniques may tackle some of these problems, but apart from their availability, many technical problems still have to be solved for many tumor locations. Repeated imaging would also deal with volume and shape changes during therapy. All this should be done in radiotherapy position, in order to avoid mismatching, image warping and other image manipulations, which all increase the chance of errors.

A weak point in current tumor delineation protocols is its manual component. Indeed, visual tumor contouring is routinely used in clinical practice. Even with carefully designed protocols, significant inter- and intraobserver variability still occur. Automated tools are therefore needed.

Positron emission tomography (PET) and, certainly, integrated PET-CT (computed tomography) have many potential advantages for radiotherapy planning. They combine anatomic and biological information in an identical patient position as radiotherapy will be delivered, there is no time interval between PET and CT scan, the CT can be used for attenuation correction, and CT densities can be used for radiation dose calculation.

Although not the aim of this article, it should be stressed that, as with any other imaging and therapeutic modality, also PET in radiotherapy should be calibrated thoroughly as well as used in strict clinical protocols. Volume assessment with PET is crucially dependent on technical factors and huge mistakes can only be avoided by sticking to well-established protocols [9].

PET with fluorodeoxyglucose (FDG) as tracer in radiotherapy planning has been investigated in many cancer types, of which non-small cell lung cancer (NSCLC) is the most widely applied in clinical practice. In other tumor types, such as head and neck cancer, neurological tumors, esophageal carcinoma, rectal cancer, lymphoma and cervical carcinoma, radiotherapy planning using FDG-PET has a role to play.

For each of these tumor types, the following questions will be addressed:

(1) Does PET scanning allow accurate tumor delineation? Does PET scanning change GTV, CTV and/or the PTV (planning target volume), both for the primary tumor and the local and regional lymph nodes?

(2) Does PET scanning allow improvement of treatment outcome?

\section{Lung Cancer \\ Non-Small Cell Lung Cancer (NSCLC) PET for Defining Tumor Volumes (Figure 1) \\ Nodal Target Volume}

Accurate identification of nodal metastases is crucial for planning curative radiotherapy, particularly as routine elective nodal irradiation is no longer recommended in NSCLC [64]. FDG-PET scan has a higher sensitivity, specificity and accuracy for detection of lymph node involvement and distant metastases in NSCLC than CT scan and, therefore, results in a more accurate staging [75].

In several planning studies, it was shown that PET or PET-CT influences the GTV [50, 51]. The PET volumes were in general smaller than with CT $[14,72]$. A prospective clinical trial using selective mediastinal radiotherapy of PETpositive nodes reported isolated nodal failures in only one of 44 patients [15]. These results were subsequently confirmed in another, similar prospective study from the Netherlands Cancer Institute [6], but not in a US retrospective series [68]. The latter may be due to the absence of a clearly defined PET delineation protocol. Although PET-defined mediastinal radiotherapy fields appear to be safe, because of a false-positive rate of approximately $30 \%$ and a false-negative rate of about $7 \%$, depending on the patient population, ideally, pathologic confirmation of PET-positive mediastinal nodes should be obtained by mediastinoscopy or endoscopic ultrasound-guided fine-needle aspiration (EUS-FNA).

\section{Target Volume for Primary Tumor}

At present, FDG-PET scans offer little additional advantage over CT or MRI (magnetic resonance imaging) scans for staging of the primary tumor because of its lack of precise anatomic localization. The spatial resolution of modern CT scanners (typically about $1 \mathrm{~mm}$ ) is far superior to that of current PET scanners (6-8 mm), so that the extra gain with fusion is expected not to be large, unless PET scans can reliably address tumor delineation caused by atelectasis or intratumor heterogeneity. However, PET did show a remarkably good correlation with pathology and patient data $[61,67,70]$. 

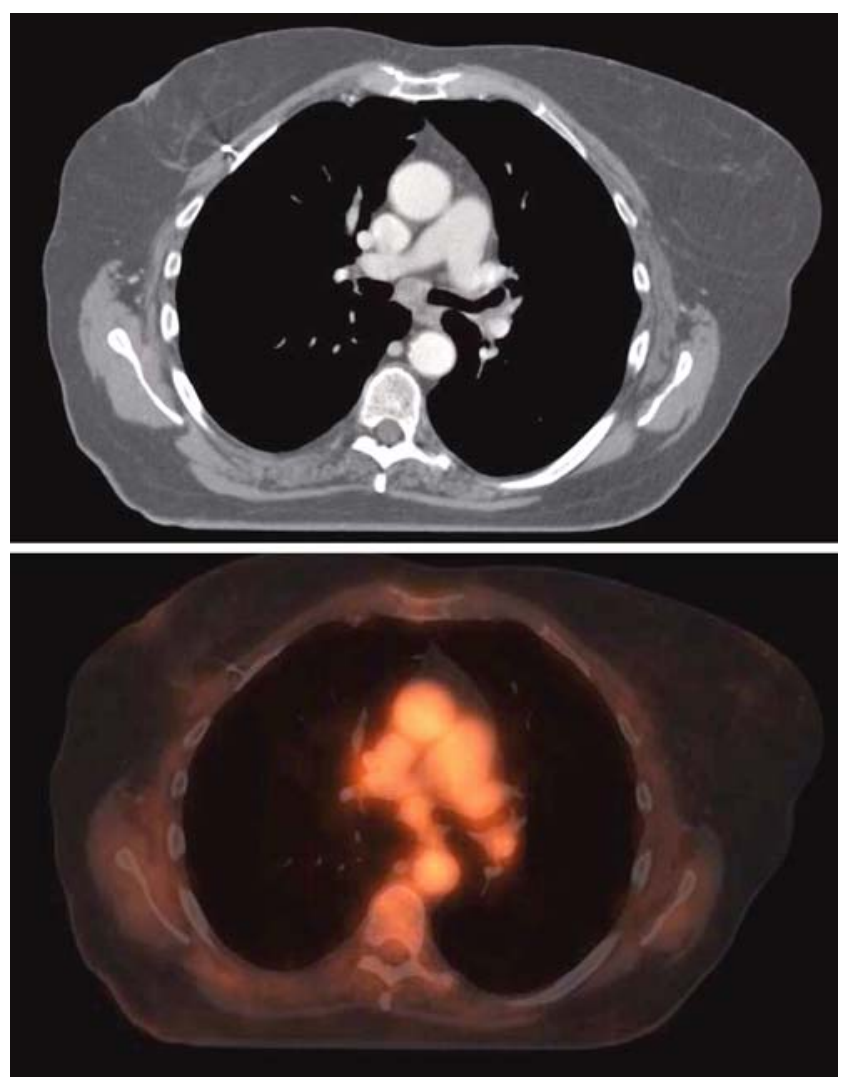

Figure 1. Non-small cell lung cancer. Axial view of ${ }^{18} \mathrm{~F}$-FDG-PET-CT with contrast. CT shows an enlarged node (level 7, diameter of $1.9 \mathrm{~cm}$ ), while PET shows no FDG uptake in level 7. This finding influences the delineation of the nodal target volume.

Abbildung 1. Nichtkleinzelliges Lungenkarzinom. Axialer Schnitt einer ${ }^{18} \mathrm{~F}$-FDG-PET-CT mit Kontrast. Das CT zeigt einen vergrößerten Lymphknoten (Level 7, Diameter 1,9 cm), während das PET keine FDG-Aufnahme in Level 7 zeigt. Dieser Befund beinflusst die Definition des nodalen Zielvolumens.

Moreover, PET scans reduced the interobserver variability compared to CT alone [45]. Integrated PET-CT scans further improved delineation variability [66]. The next step is to use the PET signal to construct automatic delineation of the tumor and to offer the radiation oncologist a solution that only needs contour editing. This method was on its turn to be less prone to variability than PET-CT [70].

As PET acquisition takes several minutes, tumor motion due to respiration or cardiac action results in PET "GTVs" that incorporate at least some effects of this motion. Respiration-gated PET acquisition techniques have been developed $[23,49]$ and are, at present, evaluated in clinical studies.

\section{Clinical Target Volume}

In view of the relatively poor spatial resolution of PET scans, it does not come as a surprise that at the time of writing, no clear advantages of PET to define the microscopic extensions of the tumor were reported. The development of new methods may change this picture in the future [67].

\section{Do PET Scans Change the Outcome of Patients with NSCLC Treated with Radiotherapy?}

PET scans have shown to detect distant metastases in up to $30 \%$ of the patients with stage III NSCLC who were M0 with conventional staging $[29,44]$. This clearly affects patient outcome, for it spares toxic therapy in individuals who will not benefit from it.

The PET volumes were, in general, smaller than with CT. The incorporation of PET in radiotherapy planning has, as previously shown, the potential to allow radiation dose escalation without increasing side effects, namely because of the reduction of radiation fields $[14,72]$. In a phase I/II trial, it was shown that this prerequisite is indeed true [71].

Whether this radiation dose increase will ultimately lead to higher cure rates is a matter of current research.

PET scans may also allow the identification of therapyresistant areas within the tumor that could be given a higher radiation dose and hence lead to a better outcome $[2,3]$.

\section{Small Cell Lung Cancer (SCLC) PET Scan for Radiotherapy of Limited-Disease Small Cell Lung Cancer}

Literature is sparse on the role of PET in limited-disease small cell lung cancer (LD-SCLC). Although after CT-based radiotherapy planning, isolated nodal recurrences may be seen in $>10 \%$ of the patients, selective nodal irradiation based on PET scans proved to result in only $3 \%$ of isolated nodal failures in a prospective study [74].

\section{Conclusions}

For NSCLC, FDG-PET allow more thorough staging, thus avoiding unnecessary treatments. In most patients, it reduces radiation treatment volumes because of the avoidance of mediastinal lymph nodes that are PET-negative and hence reduces toxicity with the same radiation dose or enables radiation dose escalation with the same toxicity. Data are also encouraging for SCLC. More research is needed to assess the effect of PET on survival. PET also reduces interobserver variability for delineating tumors and opens perspective for more automated delineation parts in radiotherapy planning, as well as innovative radiation treatment delivery.

\section{Primary Brain Tumors}

Compared with other organ systems, FDG-PET imaging of the brain presents unique challenges because of the high background glucose metabolism of normal gray matter structures. Highly metabolically active tissues such as the normal brain can mask detection of adjacent abnormalities and as such are not always helpful for tumor and target delineation. Furthermore, many primary brain tumors, for example, meningioma, show no uptake of FDG and cannot be imaged with FDG-PET. Inter- 
pretation of functional PET images can be improved by correlation with anatomic imaging. Co-registration of MRI or CT and FDG-PET images is essential for accurate evaluation of brain tumors. Also, primary brain tumors consist of a group of various pathologies and carry variable prognoses. They have the tendency to recur locally and to undergo malignant degeneration in which case PET can have added value during follow-up.

\section{Low-Grade Glioma}

Functional imaging with modern tracers such as ${ }^{11} \mathrm{C}-\mathrm{MET}$ (methionine) results in good visualization of low-grade gliomas. Baseline amino acid uptake on ${ }^{18} \mathrm{~F}$-FET-PET in a diffuse versus circumscribed tumor pattern on MRI is a strong predictor for the outcome of patients with low-grade glioma [20]. The combination of PET with conventional imaging techniques (MRI, CT) may lead to synergy in delineating these tumors in the course of radiotherapy planning. Early reports [54] found ${ }^{11} \mathrm{C}-\mathrm{MET}$ to be superior to CT in delineating gliomas. Comparing FDG-PET with MRI in 14 patients with predominantly low-grade glioma, PET volumes were larger than, equal to, or smaller than MRI-derived tumor volumes in seven, four, and three patients, respectively [53]. PET was helpful in outlining the GTV in three cases only. Jacobs et al. [30] and Kaschten et al. [37] found ${ }^{11} \mathrm{C}-\mathrm{MET}$ superior to ${ }^{18} \mathrm{~F}$-FDG and ${ }^{18} \mathrm{~F}$-FLT $\left({ }^{18} \mathrm{~F}\right.$ fluoro-3'-deoxy-3'-L-fluorothymidine) respectively, in delineating low-grade glioma. For low-grade glioma, an amino acid tracer is the tracer of first choice in radiotherapy planning.

\section{Pituitary Adenoma}

The value of ${ }^{18} \mathrm{~F}$-FDG and ${ }^{11} \mathrm{C}$-MET in addition to MRI was investigated in a population of 57 patients comprising a variety of tumors including ten pituitary adenomas [41, 42]. PET influenced the target volume in $69 \%$ of the target volumes for stereotactic radiosurgery. In recurrent adenoma after surgery, ${ }^{11} \mathrm{C}$-MET may distinguish between active tumor and fibrosis, which is essential to define an optimal target volume for radiotherapy purposes [8].

\section{High-Grade Glioma (Figure 2)}

Studies comparing tumor volumes based on PET (both ${ }^{18} \mathrm{~F}-\mathrm{FDG}$ and ${ }^{11} \mathrm{C}-\mathrm{MET}$ ) and other imaging modalities usually show that PET scan volumes are smaller than MRI- and CT-based volumes [24, 27]. In a study of 57 patients treated by radiosurgery for 72 target volumes, an abnormal uptake of FDG or ${ }^{11} \mathrm{C}$-MET on PET was seen in $86 \%$ of the targets, leading to a change in target volume in $69 \%$ of these cases compared to MRI delineation [41]. In $36 \%$ of these patients, the PET-based volume was fully encompassed with the MRI-based volume, while in 18 cases, PET showed a target volume outside the MRI-based delineation.

Using FDG-PET, in 22 out of 27 patients with glioblastoma, the tumor volumes were at least $25 \%$ smaller on FDG-PET than on MRI [69]. Occasionally, there was FDG uptake outside the region with gadolinium enhancement on MRI. Another

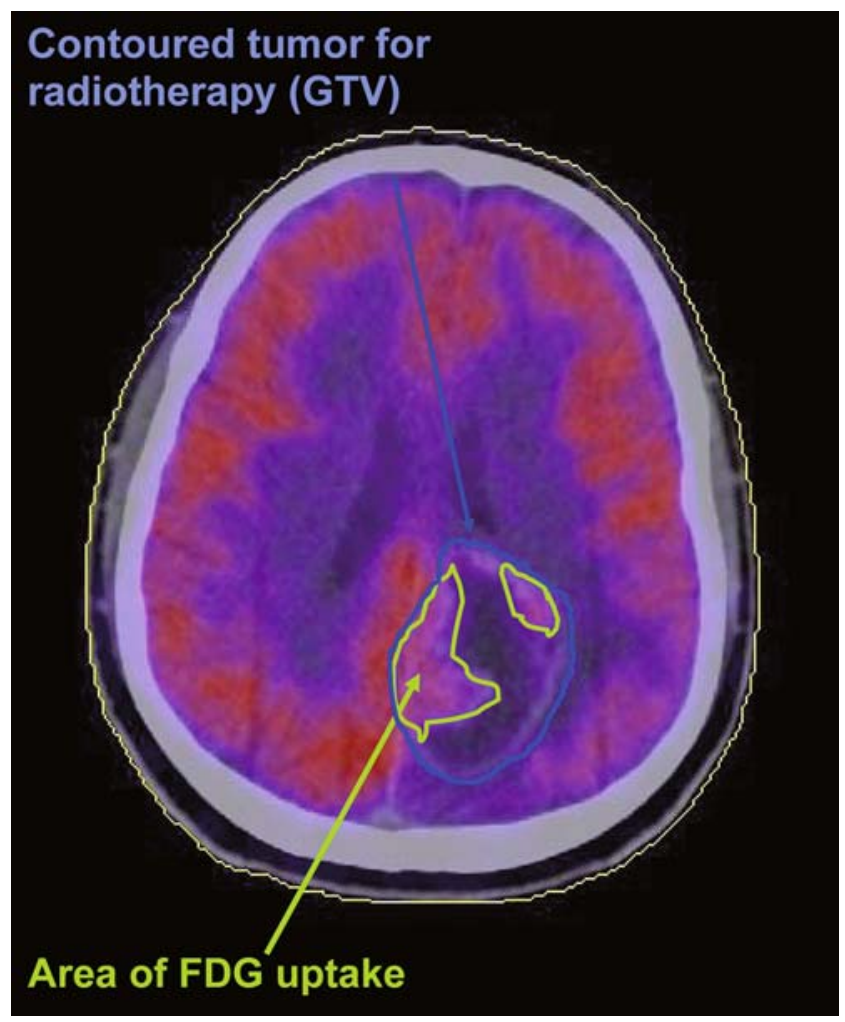

Figure 2. Glioblastoma. Axial view of ${ }^{18} \mathrm{~F}-\mathrm{FDG}$-PET-CT with contrast. The area of the postoperative tumor volume for radiotherapy is defined in blue. Yellow areas are those of FDG uptake. Volumes are usually within the contrast-enhanced area of CT and MRI. The normal brain shows high uptake of FDG in general and makes a clear distinction between tumor and normal brain difficult.

Abbildung 2. Glioblastom. Axialer Schnitt einer ${ }^{18} \mathrm{~F}$-FDG-PET-CT mit Kontrast. Das Gebiet des postoperativen Tumorvolumens für die Strahlentherapie ist in Blau wiedergegeben. Das grüngelbe Areal stellt das FDG-Aufnahmegebiet dar. Die Volumina sind üblicherweise innerhalb des kontrastverstärkten Gebiets der CT und MRT lokalisiert. Da das normale Gehirn generell eine hohe FDG-Aufnahme zeigt, sind klare Unterscheidungen zwischen Tumor und normalem Hirngewebe schwierig.

study confirmed a decrease in mean volumes on FDG-PET as compared to MRI (T1-weighted images with gadolinium) [24].

By contrast, an increase in GTV with the use of ${ }^{11} \mathrm{C}-\mathrm{MET}$ in $79 \%$ of the patients compared to MRI was reported [25]. This was confirmed by another study [47]. A first study comparing patients with recurrent high-grade gliomas reirradiated using ${ }^{11} \mathrm{C}-\mathrm{MET}$-PET-based tumor delineation versus CT/MR images for treatment planning showed an improvement in survival [27]. Whether ${ }^{11} \mathrm{C}$-MET-PET-defined tumor volumes for radiation treatment planning and, as a consequence, extended radiation fields will have a significant influence on outcome in terms of overall survival, has to be proven in future studies.

Additionally, PET can reduce interobserver variability in delineation of brain tumors. Van Laere et al. compared FDG and ${ }^{11} \mathrm{C}$-MET-PET for the delineation of brain tumors [73]. 
The interobserver agreement was $100 \%$ for ${ }^{11} \mathrm{C}$-MET and $73 \%$ for FDG-PET. Many high-grade gliomas show intratumor heterogeneity and PET could be used to define tumor regions being at high risk for recurrence. Regions with abnormal tracer uptake (reported for FDG or FET $\left[{ }^{18} \mathrm{~F}-\right.$ fluoroethyltyrosine]) are at risk for first tumor progression and could therefore be a target for dose escalation [59, 65, 79]. Areas of FET uptake on FET-PET-CT for radiotherapy planning were being observed up to $20 \mathrm{~mm}$ outside the area of gadolinium enhancement on MRI [79].

\section{Meningioma}

A small study of ten patients treated with fractionated stereotactic radiotherapy showed a significant increase of the GTV, when ${ }^{11} \mathrm{C}$-MET-PET was used for tumor delineation [26]. The addition of ${ }^{11} \mathrm{C}-\mathrm{MET}$-PET was beneficial for GTV delineation in all but three out of 32 patients. Radiotherapy planning for skull base meningiomas influenced the GTV, possibly resulting in an increase, as well as in a decrease [5]. ${ }^{68} \mathrm{Ga}$-DOTATOC-PET delivered additional information concerning tumor extension in all investigated patients planned for fractionated stereotactic radiotherapy of meningiomas [46].

In $73 \%$ of the patients, the planning tumor volume was significantly modified, and in one patient, no tumor was exactly identified on CT/MRI but was visible on PET.

Another tracer currently being tested is ${ }^{18} \mathrm{~F}$-tyrosine. This tracer is also taken up by meningiomas with a tumor-to-cortex ratio of $2.53 \pm 0.35[60)$. The ${ }^{18} \mathrm{~F}$-tyrosine anomalies completely overlapped with the MR image in $54 \%$, extended beyond the MRI lesion in $38 \%$, and were smaller in $8 \%$ of the tumors. Meningiomas of the skull base are clearly visualized using ${ }^{18} \mathrm{~F}$-tyrosine PET, even after radiotherapy.

\section{Conclusions}

FDG-PET is mainly used in brain tumors for definition of tumor grading and prognosis as well as differentiation between recurrence and radionecrosis. Tumor delineation for radiotherapy planning was not substantially influenced, as physiologically, the most intense FDG uptake is seen in brain tissue. Therefore, the tracer is not very suitable for the imaging of most intracerebral malignancies.

For low- and high-grade gliomas and meningiomas, ${ }^{11} \mathrm{C}$-MET or other amino acid tracers such as tyrosine are currently the tracers of first choice in radiotherapy planning. First data have shown a survival advantage for patients with a high-grade glioma, if MET-PET-based radiotherapy planning was used. However, further investigation is needed.

\section{Esophageal Carcinoma PET for Defining Tumor Volumes Nodal Target Volume}

Nodal staging using FDG-PET is limited by local tumor invasion. Consequently, the accuracy of staging regional node metastases decreases with an accuracy rate of $24-90 \%$ for PET compared with 40-73\% for CT. The reported sensitivity and specificity of FDG-PET regarding nodal staging was $24-72 \%$ and $82-100 \%$, respectively $[18,28,58]$. Generally, FDG-PET has a higher specificity ( $89 \%$ vs. $67 \%$ ) with a lower sensitivity (33\% vs. $81 \%$ ) for identifying nodal metastases compared with the use of combined CT/EUS-FNA. The lower sensitivity of FDG-PET for detecting local lymph nodes depends on the limited spatial resolution of PET with a difficulty to discriminate the primary tumor from local, peritumoral lymph nodes.

Vrieze et al. assessed lymph node involvement by CT, EUS, and FDG-PET in 30 patients with advanced esophageal carcinoma [78]. In $47 \%$ of patients, discordance was noted between lymph nodes detected by FDG-PET and by CT/EUS. The authors suggested that irradiated volumes should not be reduced based on negative FDG-PET results, given the false-negatives noted in this report. However, they also concluded that FDG-PET demonstrated adequate specificity to conclude that FDG-PET-positive disease should be included in the irradiated volume. As these patients received neoadjuvant chemoradiation, no histological confirmation of discordant findings is possible.

\section{Target Volume for Primary Tumor}

Konski et al. performed CT and FDG-PET for radiation treatment planning in 25 patients with esophageal carcinoma; 18 of the 25 patients also had EUS for comparison [39]. Mean GTV as determined by CT scan was significantly bigger than that determined by FDG-PET. EUS detected more regional adenopathy than both CT and PET. Moureau-Zabotto et al. performed FDG-PET and CT for simulation purposes in 34 patients with esophageal carcinoma [48]. Five fiducial markers were used to precisely co-register the CT and FDG-PET images for planning purposes. GTV was reduced in $35 \%$ and increased in $21 \%$ of patients. Leong et al. enrolled 21 esophageal carcinoma patients in a prospective trial to determine effects of PET-CT on delineation of tumor volume for radiotherapy planning [40]. PET-CT detected disease in eight patients that was not detected by CT scan: four of these patients were found to have metastatic disease and four had regional nodal disease. In 16 of 21 patients who proceeded to the radiotherapy planning phase of the trial, $69 \%$ had PET-CT-positive disease that would have been excluded, if $\mathrm{CT}$ alone had been used for radiation treatment planning.

\section{Do PET Scans Change the Outcome of Patients with Esophageal Cancer Treated with Radiotherapy?}

Well-performed FDG-PET improves the selection of patients with esophageal cancer for potentially curative surgery, especially in stages III-IV [76]. This clearly affects patient outcome, since it saves an extra complication and mortality risk in individuals who will not benefit from surgery. The incorporation of PET in radiotherapy planning has, as previously shown, the potential to allow radiation dose escalation with- 
out increasing side effects, namely because of the reduction of radiation fields.

\section{Conclusions}

A well-performed FDG-PET-CT is important to detect distant metastases and hence to select patients suitable for local therapy. For the nodal target volume, FDG-PET has a higher specificity with a lower sensitivity compared with the use of combined CT/EUS-FNA. FDG-PET results in a smaller GTV in most of the patients analyzed. If validated, the use of FDG-PET might result in a smaller target volume, which would reduce the toxicity or enable radiation dose escalation with the same toxicity.

\section{Rectal Cancer \\ PET for Defining Tumor Volumes (Figure 3) Nodal Target Volume}

Studies investigating the role of FDG-PET for the initial staging of rectal cancer suggest that PET is useful in the diagnosis of the primary tumor, but it is of limited value for detecting regional lymph node metastases, with a sensitivity of only about $30 \%[1,36]$.

Irradiated volumes should therefore not be reduced based on negative FDG-PET results. However, as the positive predictive value was approximately $90 \%$, FDG-PET-positive disease should be included in the irradiated volume.

\section{Target Volume for Primary Tumor}

FDG-PET represents the imaging technique of choice to discriminate between benign or malignant tumors of presacral residual postsurgical masses in rectal cancer patients [19], although infection can lead to false-positive findings. The data on the use of FDG-PET for radiation treatment planning in rectal cancers is limited. Ciernik et al. evaluated the value of PET-CT on radiotherapy planning for patients with tumors at several sites, including carcinoma of the rectum (six patients) and carcinoma of the anus (seven patients) [12]. The GTV increased in three of six patients with rectal primaries,
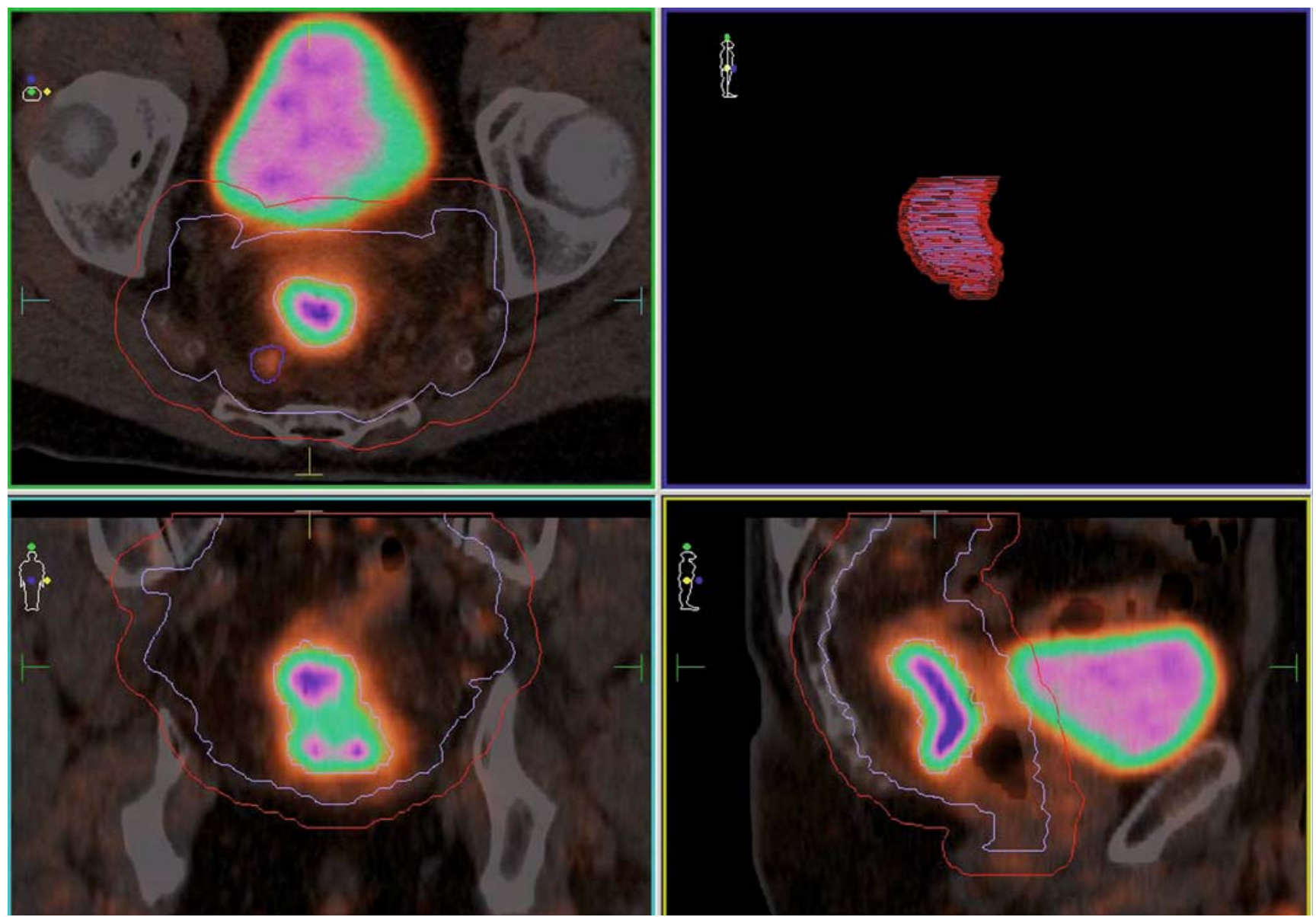

Figure 3. Delineation of the GTV, CTV, and PTV on the basis of an ${ }^{18} \mathrm{~F}-\mathrm{FDG}-\mathrm{PET}-\mathrm{CT}$ from a patient with midrectal cancer. GTV is light brown, the enlarged PET-positive mesorectal lymph node blue, the CTV light blue, and the PTV red.

Abbildung 3. Einzeichnung des GTV, CTV und PTV auf Basis einer ${ }^{18} \mathrm{~F}$-FDG-PET-CT eines Patienten mit einem mittleren Rektumkarzinom. Das GTV ist hellbraun, der vergrößerte PET-positive mesorektale Lymphknoten blau, das CTV hellblau und das PTV rot dargestellt. 
with a mean GTV increase of $50 \%$ and a PTV increase of $20 \%$. Several groups have investigated the impact of PET-CT use on the treatment and the radiotherapy volume definitions [4, 12, 55, 77]. Significant tumor volume changes were observed. However, even if PET can provide additional functional information, its usefulness in the treatment of rectal cancer is still questionable and needs to be evaluated in prospective trials with strict methodology. Its benefit may be of little interest in preoperative three-dimensional conformal radiotherapy, as the total mesorectum included in the CTV will be surgically removed anyway. However, it may become important, when higher doses in relevant biological regions need to be achieved with boost techniques [55].

Several studies have demonstrated the substantial variability among radiation oncologists in defining the target volume using CT images. At the time of writing, it remains unclear as to whether PET-based delineation accurately represents the real macroscopic tumor extension.

\section{Clinical Target Volume}

In general, the current treatment regimens for rectal cancer question the additive value for the use of PET-CT in the definition of the CTV, since the total mesorectum included in the CTV will be surgically removed anyway.

\section{Do PET Scans Change the Outcome of Patients with Rectal Cancer Treated with Radiotherapy?}

The incorporation of PET in radiotherapy planning has the potential to allow radiation dose escalation without increasing side effects, this because of the reduction of radiation fields. Whether this radiation dose increase will ultimately lead to higher cure rates or less surgical resections with, as a result, less complications is a matter of current research. A more individualized approach based on early treatment response might have the advantage of a response-adjusted radiation treatment with the goal of more complete tumor responses.

This could then help to avoid unnecessary surgical resections, thereby improving outcome and quality of life. Published data indicate that PET-CT has a high predictive value in the therapeutic management of rectal cancer [10, 31-34]. This could be an asset for improving patient care by reducing the effort, cost, and morbidity associated with ineffective treatment in nonresponders. The available studies on preoperative radiochemotherapy indicate that PET-CT is a significant predictor of therapy outcome and correlates better with pathology than morphological imaging modalities. Since PET-CT is able to predict the final outcome, it may be used to guide treatment regimens in the near future, thereby better individualizing treatment while improving the patients' outcome.

\section{Conclusions}

Although FDG-PET-CT is of limited value for detecting regional lymph node metastases, its high positive predictive value may change irradiation volumes. In spite of the fact that the current radiotherapy treatment of rectal cancer includes the whole mesorectum, which will be surgically removed anyway, future developments may involve FDG-PET in patient selection suitable for nonsurgical therapy as well as for more sophisticated radiation treatment delivery.

\section{Lymphoma}

PET for Defining Tumor Volumes

FDG-PET is superior to CT or MRI for the staging of both non-Hodgkin's and Hodgkin's lymphoma [16]. Early assessment of FDG uptake in the tumor during chemotherapy is highly predictive for subsequent outcome, as is residual FDG avidity after treatment $[38,63,82]$. With the concept of involved-node irradiation in Hodgkin's disease [17, 22, 81], increased interest has emerged to include FDG-PET scan information for defining target volumes [21]. After chemotherapy, the initial FDG-PET helped the delineation of involved-node radiotherapy fields due to the identification of lymph nodes that were undetected on CT in $36 \%$ of the patients. Prechemotherapy FDG-PET data were thus essential for correctly implementing the involved-node radiotherapy concept.

\section{Do PET Scans Change the Outcome of Patients with Lymphoma Treated with Radiotherapy?}

No trials have been completed thus far that address this question, but in view of the decreased irradiation volumes [81] and, at the same time, the decreased probability of geographic miss [21], it is very likely that the inclusion of FDG-PET information improves the outcome of patients with Hodgkin's disease.

\section{Conclusions}

In Hodgkin's disease, FDG-PET is essential for involved-node irradiation and leads to decreased irradiation volumes while also decreasing geographic miss.

\section{Cervical Carcinoma \\ PET for Defining Tumor Volumes (Figures 4 and 5) \\ Target Volume for Primary Tumor}

The sensitivity of FDG-PET for detecting local disease ranges between $91 \%$ and $100 \%$. Due to the limitations in spatial resolution, PET imaging is inaccurate for assessing local tumor extension in adjacent structures such as the parametrium. For this purpose, MRI is the modality of choice [7].

\section{Nodal Target Volume}

Due to the small risk of lymphatic spread in early-stage cervical cancer, the sensitivity of PET is low [80]. In locally advanced cervical carcinoma, biological PET criteria have been demonstrated to be superior to morphological MRI criteria for assessing retroperitoneal metastases [11]. In case of spread to the para-aortic nodes, about one third of the patients may still be cured following extended-field radiotherapy. FDG-PET is the most accurate technique for evaluating para-aortic lymph nodes [43]. Identification of gross tumor deposits will change 


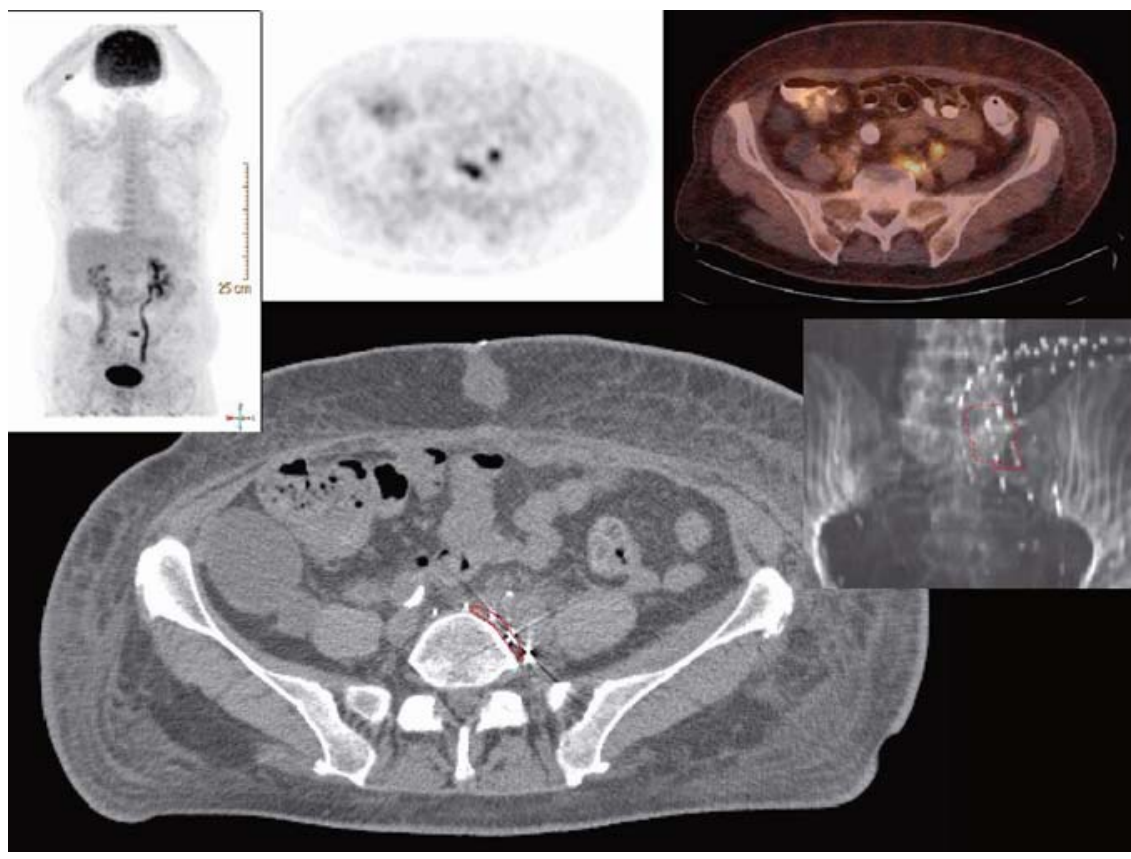

Figure 4. Cervical cancer. Patient presenting with isolated lymphatic recurrence 15 months following initial treatment with chemoradiation. Treatment consisted of gross tumor resection with subsequent high-dose-rate brachytherapy delivered to the tumor bed.

Abbildung 4. Zervixkarzinom. Die Patientin stellte sich 15 Monate nach der initialen Radiochemotherapie mit einem isolierten Lymphknotenrezidiv vor. Die Behandlung bestand aus einer Tumorresektion, gefolgt von einer konsolidierenden High-Dose-Rate-Brachytherapie auf das Tumorbett.

the radiation treatment volume and/or total dose in locally advanced disease.

\section{Do PET Scans Change the Outcome of Patients with Cervical Cancer Treated with Radiotherapy?}

At present, no randomized study has been performed to answer this question. However, in view of the detection of otherwise unrecognized nodal disease in the para-aortic region that can be irradiated with curative intent, a significant gain can reasonably be expected.

Although definite conclusions cannot be drawn yet on determining cutoff values for $\mathrm{SUV}_{\max }$ (standardized uptake value), integration of $\mathrm{SUV}_{\max }$ in clinical studies as an additional prognostic marker seems warranted. So far, changes in metabolic response observed during treatment did not correlate with survival outcome, whereas posttreatment evaluation seems to be a reliable measure for treatment outcome enabling decision-taking regarding additional salvage treatment.

\section{Conclusions}

Currently, FDG-PET is the imaging modality of first choice for assessing lymphatic spread in locally advanced disease. Its role in providing additional prognostic information with impact on primary treatment decision-making needs to be evaluated in prospective clinical trials.

\section{Head and Neck Cancer}

PET for Defining Tumor Volumes

An in-depth comparison between FDG-PET, MRI and CT scans with the histology of resection specimen showed that FDG-PET may be the most accurate of the three for the detection of head and neck cancer [52]. Tumor volume determined by FDG-PET tends to be smaller than the volume determined by the other modalities, but most closely approximates the pathologic tumor volume [13]. However, some tumor regions that are apparent on CT or MRI may not be imaged on PET, or the reverse may occur. PET-based delineation of the primary tumor is, at present, not ready for clinical routine [57].

\section{PET for Defining Nodal Volumes}

FDG-PET often changes the nodal staging in head and neck cancer [56]. However, many lymph nodes that are enlarged and considered metastatic by standard CT-based criteria are negative on FDG-PET scan [62]. On the other hand, a small proportion of marginally enlarged nodes are positive on FDG-PET scan. However, as the results are largely dependent on the PET segmentation tool used, until proper validation with pathology, FDG-PET cannot be recommended for target volume definition of metastatic lymph nodes in routine radiotherapy.

\section{Do PET Scans Change the Outcome of Patients with Head and Neck Cancer Treated with Radiotherapy?} Besides for staging purposes, such as for carcinoma with unknown primary [35], for purely radiotherapy purposes, FDG-PET has not shown to be beneficial for head and neck cancer patients.

\section{Conclusions}

FDG-PET-defined tumor volumes are more closely related to pathology than those determined by CT and MRI, but both over- and underestimation still occur. Besides for staging purposes, FDG-PET is not recommended for routine radiotherapy delineation purposes.

\section{General Conclusions}

FDG-PET plays an increasingly important role in radiotherapy, beyond staging and selection of patients. Especially for NSCLC, FDG-PET has led to the safe decrease of radiotherapy volumes, enabling radiation dose escalation and, experimentally, redistribution of radiation doses within the 


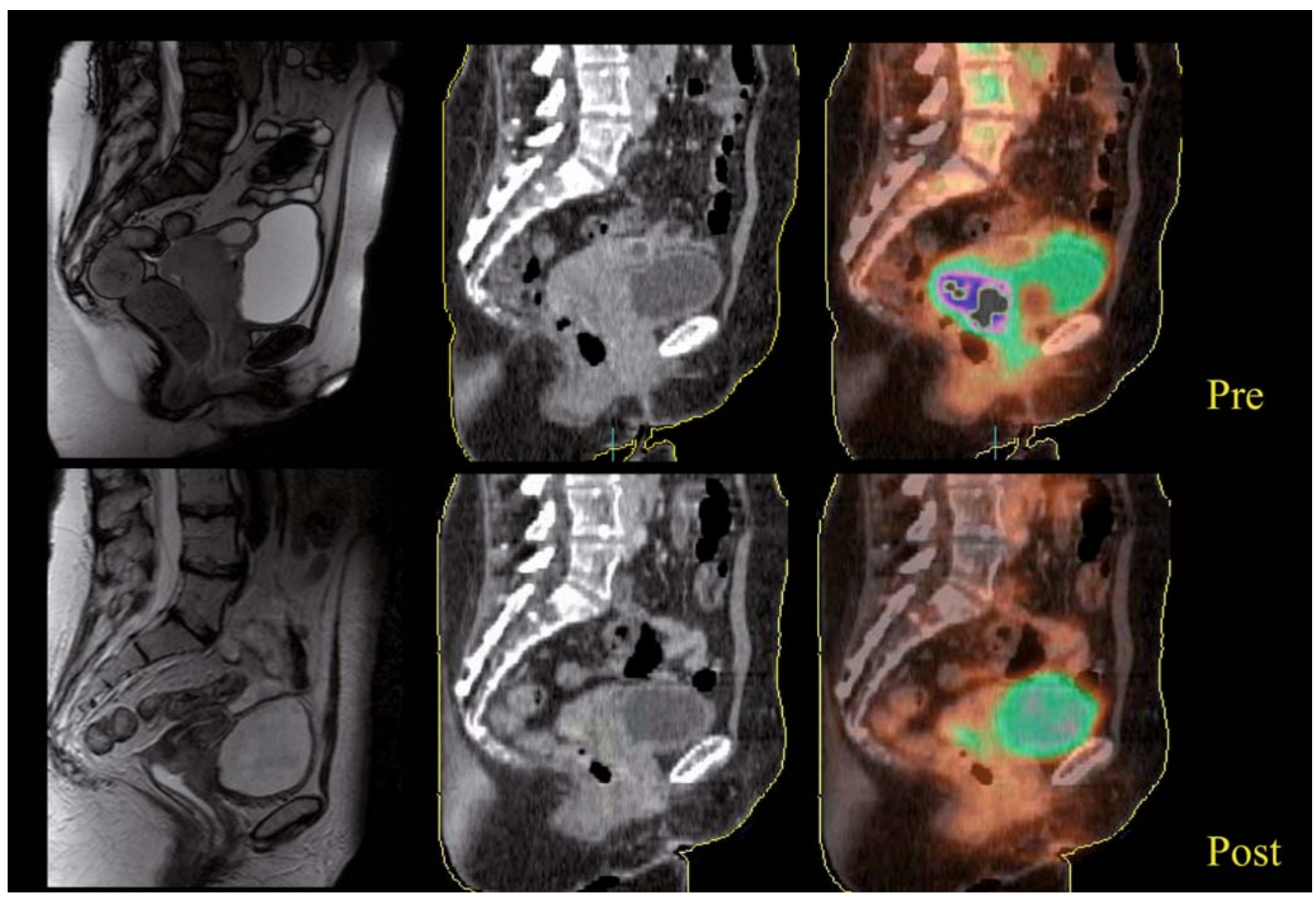

Figure 5. Tumor response in a patient with cervix carcinoma FIGO stage IVA (extension to bladder) following 50 Gy of external-beam radiotherapy plus hyperthermia as determined with MRI, CT, and FDG-PET.

Abbildung 5. MRT-, CT- und FDG-PET-Darstellung der Tumorreduktion bei einer Patientin mit Zervixkarzinom FIGO-Stadium IVA (Ausdehnung bis zur Harnblase) nach 50 Gy externer Strahlentherapie in Kombination mit Hyperthermie.

tumor. In LD-SCLC, the role of FDG-PET is emerging. For low-grade gliomas, ${ }^{11} \mathrm{C}$-MET is the tracer of first choice in radiotherapy planning. PET for high-grade gliomas is investigational.

For esophageal and rectal cancer, the main advantage of FDG-PET is the detection of otherwise unrecognized lymph node metastases. In Hodgkin's disease, FDG-PET is essential for involved-node irradiation and leads to decreased irradiation volumes while also decreasing geographic miss. FDG-PET's major role in the treatment of cervical cancer with radiation lies in the detection of para-aortic nodes that can be encompassed in radiation fields. Besides for staging purposes, FDG-PET is not recommended for routine radiotherapy delineation purposes.

It should be emphasized that using PET is only safe, when adhering to strictly standardized protocols.

\section{References}

1. Abdel-Nabi H, Doerr RJ, Lamonica DM, et al. Staging of primary colorectal carcinomas with fluorine-18 fluorodeoxyglucose whole-body PET: correlation with histopathologic and CT findings. Radiology 1998;206:755-60.

2. Aerts HJ, Bosmans G, van Baardwijk AA, et al. Stability of (18)F-deoxyglucose uptake locations within tumor during radiotherapy for NSCLC: a prospective study. Int J Radiat Oncol Biol Phys 2008;71:1402-7.

3. Aerts $\mathrm{HJ}$, van Baardwijk AA, Petit SF, et al. Identification of residual metabolic-active areas within individual NSCLC tumours using a pre-radiotherapy (18)fluorodeoxyglucose-PET-CT scan. Radiother Oncol 2009:91:386-92.

4. Anderson C, Koshy M, Staley C, et al. PET-CT fusion in radiation management of patients with anorectal tumors. Int J Radiat Oncol Biol Phys 2007;69:155-62.

5. Astner ST, Dobrei-Ciuchendea M, Essler M, et al. Effect of 11C-methionine-positron emission tomography on gross tumor volume delineation in stereotactic radiotherapy of skull base meningiomas. Int J Radiat Oncol Biol Phys 2008;72:1161-7.

6. Belderbos JS, Heemsbergen WD, De Jaeger K, et al. Final results of a phase I/II dose escalation trial in non-small-cell lung cancer using three-dimensional conformal radiotherapy. Int J Radiat Oncol Biol Phys 2006; 66:126-34. 
7. Belhocine $T$, Thille A, Fridman V, et al. Contribution of whole-body $18 \mathrm{FDG}$ PET imaging in the management of cervical cancer. Gynecol Oncol 2002; 87:90-7.

8. Bergström M, Muhr C, Lundberg P0, Långström B. PET as a tool in the clinical evaluation of pituitary adenomas. J Nucl Med 1991;32:610-5.

9. Boellaard R, Oyen WJ, Hoekstra CJ, et al. The Netherlands protocol for standardisation and quantification of FDG whole body PET studies in multi-centre trials. Eur J Nucl Med Mol Imaging 2008;35:2320-33.

10. Capirci C, Rubello D, Pasini F, et al. The role of dual-time combined 18-fluorodeoxyglucose positron emission tomography and computed tomography in the staging and restaging workup of locally advanced rectal cancer, treated with preoperative chemoradiation therapy and radical surgery. Int J Radiat Oncol Biol Phys 2009;74:1461-9.

11. Choi HJ, Roh JW, Seo SS, et al. Comparison of the accuracy of magnetic resonance imaging and positron emission tomography/computed tomography in the presurgical detection of lymph node metastases in patients with uterine cervical carcinoma: a prospective study. Cancer 2006;106: 914-22.

12. Ciernik IF, Dizendorf E, Baumert BG, et al. Radiation treatment planning with an integrated positron emission and computer tomography (PET/CT): a feasibility study. Int J Radiat Oncol Biol Phys 2003;57:853-63.

13. Daisne JF, Duprez T, Weynand B, et al. Tumor volume in pharyngolaryngeal squamous cell carcinoma: comparison at CT, MR imaging, and FDG PET and validation with surgical specimen. Radiology 2004;233:93-100.

14. De Ruysscher D, Wanders S, Minken A, et al. Effects of radiotherapy planning with a dedicated combined PET-CT-simulator of patients with non-small cell lung cancer on dose limiting normal tissues and radiation dose-escalation: results of a prospective study. Radiother Oncol 2005;77:5-10.

15. De Ruysscher D, Wanders S, van Haren E, et al. Selective mediastinal node irradiation on basis of the FDG-PET scan in patients with non-small cell lung cancer: a prospective clinical study. Int $\mathrm{J}$ Radiat Oncol Biol Phys 2005;62:988-94.

16. Divgi C. Imaging: staging and evaluation of lymphoma using nuclear medicine. Semin Oncol 2005;32:Suppl 1:S11-8.

17. Eich HT, Müller RP, Engenhart-Cabillic R, et al., German Hodgkin Study Group. Involved-node radiotherapy in early-stage Hodgkin's lymphoma. Definition and guidelines of the German Hodgkin Study Group (GHSG). Strahlenther Onkol 2008;184:406-10.

18. Flamen $\mathrm{P}$, Lerut A, Van Cutsem $\mathrm{E}$, et al. Utility of positron emission tomography for the staging of patients with potentially operable esophageal carcinoma. J Clin Oncol 2000;18:3202-10.

19. Flamen P, Stroobants S, Van Cutsem E, et al. Additional value of whole-body positron emission tomography with fluorine-18-2-fluoro-deoxy-D-glucose in recurrent colorectal cancer. J Clin Oncol 1999;17:894-901.

20. Floeth FW, Sabel M, Stoffels G, et al. Prognostic value of 0-(2-1F-fluoroethyl)-L-tyrosine PET and MRI in low-grade glioma. J Nucl Med 2007;48:519-27.

21. Girinsky T, Ghalibafian M, Bonniaud G, et al. Is FDG-PET scan in patients with early stage Hodgkin lymphoma of any value in the implementation of the involved-node radiotherapy concept and dose painting? Radiother Oncol 2007;85:178-86.

22. Girinsky $T$, van der Maazen $R$, Specht $L$, et al. Involved-node radiotherapy (INRT) in patients with early Hodgkin lymphoma: concepts and guidelines. Radiother Oncol 2006;79:270-7.

23. Grgic A, Nestle U, Schaefer-Schuler A, et al. FDG-PET-based radiotherapy planning in lung cancer: optimum breathing protocol and patient positioning - an intraindividual comparison. Int $\mathrm{J}$ Radiat Oncol Biol Phys 2009;73:103-11.

24. Gross MW, Weber WA, Feldmann HJ, et al. The value of F-18-fluorodeoxyglucose PET for the 3-D radiation treatment planning of malignant gliomas. Int J Radiat Oncol Biol Phys 1998;41:989-95.

25. Grosu AL, Piert M, Molls M. Experience of PET for target localisation in radiation oncology. Br J Radiol Suppl 2005;28:8-32.

26. Grosu AL, Weber WA, Astner ST, et al. $11 \mathrm{C}$-methionine PET improves the target volume delineation of meningiomas treated with stereotactic fractionated radiotherapy. Int J Radiat Oncol Biol Phys 2006;66:339-44.

27. Grosu AL, Weber WA, Franz M, et al. Reirradiation of recurrent high-grade gliomas using amino acid PET (SPECT)/CT/MRI image fusion to determine gross tumor volume for stereotactic fractionated radiotherapy. Int J Radiat Oncol Biol Phys 2005;63:511-9.

28. Heeren $\mathrm{PA}$, Jager $\mathrm{PL}$, Bongaerts $\mathrm{F}$, et al. Detection of distant metastases in esophageal cancer with (18)F-FDG PET. J Nucl Med 2004;45:980-7.

29. Hicks RJ, Kalff V, MacManus MP, et al. 18F-FDG PET provides high-impact and powerful prognostic stratification in staging newly diagnosed non-small cell lung cancer. J Nucl Med 2001;42:1596-604.

30. Jacobs AH, Thomas A, Kracht LW, et al. 18F-fluoro-L-thymidine and $11 \mathrm{C}$-methylmethionine as markers of increased transport and proliferation in brain tumors. J Nucl Med 2005;46:1948-58.

31. Janssen $\mathrm{MH}$, Aerts HJ, Öllers MC, et al. Tumor delineation based on time-activity curve differences assessed with dynamic fluorodeoxyglucose positron emission tomography-computed tomography in rectal cancer patients. Int J Radiat Oncol Biol Phys 2009;73:456-65.

32. Janssen $M H$, Ollers MC, Riedl RG, et al. Accurate prediction of pathological rectal tumor response after two weeks of preoperative radiochemotherapy using (18)F-fluorodeoxyglucose-positron emission tomography-computed tomography imaging. Int J Radiat Oncol Biol Phys 2010;77:392-9.

33. Janssen MH, Ollers MC, Stiphout RG, et al. Blood glucose level normalization and accurate timing improves the accuracy of PET-based treatment response predictions in rectal cancer. Radiother Oncol 2010;95: 203-8.

34. Janssen MH, Ollers MC, van Stiphout RG, et al. Evaluation of early metabolic responses in rectal cancer during combined radiochemotherapy or radiotherapy alone: sequential FDG-PET-CT findings. Radiother Oncol 2010; 94:151-5.

35. Johansen J, Buus S, Loft A, et al. Prospective study of 18FDG-PET in the detection and management of patients with lymph node metastases to the neck from an unknown primary tumor. Results from the DAHANCA-13 study. Head Neck 2008;30:471-8.

36. Kantorova I, Lipska L, Belohlavek 0, et al. Routine 18F-FDG PET preoperative staging of colorectal cancer: comparison with conventional staging and its impact on treatment decision making. J Nucl Med 2003;44:1784-8.

37. Kaschten B, Stevenaert A, Sadzot B, et al. Preoperative evaluation of 54 gliomas by PET with fluorine-18-fluorodeoxyglucose and/or carbon-11-methionine. J Nucl Med 1998;39:778-85.

38. Kobe C, Dietlein M, Franklin J, et al. Positron emission tomography has a high negative predictive value for progression or early relapse for patients with residual disease after first-line chemotherapy in advanced-stage Hodgkin lymphoma. Blood 2008;112:3989-94.

39. Konski A, Doss M, Milestone B, et al. The integration of 18-fluoro-deoxy-glucose positron emission tomography and endoscopic ultrasound in the treatment-planning process for esophageal carcinoma. Int $\mathrm{J}$ Radiat Oncol Biol Phys 2005;61:1123-8.

40. Leong $T$, Everitt $C$, Yuen $K$, et al. A prospective study to evaluate the impact of FDG-PET on CT based radiotherapy treatment planning for oesophageal cancer. Radiother Oncol 2006;78:254-61.

41. Levivier M, Massager N, Wikler D, et al. Use of stereotactic PET images in dosimetry planning of radiosurgery for brain tumors: clinical experience and proposed classification. J Nucl Med 2004;45:1146-5.

42. Levivier M, Massager N, Wikler D, Goldman S. Modern multimodal neuroimaging for radiosurgery: the example of PET scan integration. Acta Neurochir (Wien) 2004;91:1-7.

43. Loft $A$, Berthelsen AK, Roed $H$, et al. The diagnostic value of PET/CT scanning in patients with cervical cancer: a prospective study. Gynecol Oncol 2007;106:29-34.

44. MacManus MP, Hicks RJ, Matthews JP, et al. High rate of detection of unsuspected distant metastases by PET in apparent stage III non-small-cell lung cancer: implications for radical radiation therapy. Int J Radiat Oncol Biol Phys 2001;50:287-93.

45. Mah K, Caldwell CB, Ung YC, et al. The impact of (18)FDG-PET on target and critical organs in CT-based treatment planning of patients with poorly defined non-small-cell lung carcinoma: a prospective study. Int J Radiat Oncol Biol Phys 2002;52:339-50.

46. Milker-Zabel S, Zabel-du Bois A, Henze M, et al. Improved target volume definition for fractionated stereotactic radiotherapy in patients with intracranial meningiomas by correlation of CT, MRI, and [68Ga]-DOTATOC-PET. Int J Radiat Oncol Biol Phys 2006;65:222-7. 
47. Miwa K, Shinoda J, Yano H, et al. Discrepancy between lesion distributions on methionine PET and MR images in patients with glioblastoma multiforme: insight from a PET and MR fusion image study. J Neurol Neurosurg Psychiatry 2004;75:1457-62.

48. Moureau-Zabotto L, Touboul E, Lerouge D, et al. Impact of CT and 18F-deoxyglucose positron emission tomography image fusion for conformal radiotherapy in esophageal carcinoma. Int J Radiat Oncol Biol Phys 2005;63:340-5.

49. Nehmeh SA, Erdi YE, Rosenzweig KE, et al. Reduction of respiratory motion artifacts in PET imaging of lung cancer by respiratory correlated dynamic PET: methodology and comparison with respiratory gated PET. J Nucl Med 2003;44:1644-8.

50. Nestle U, Kremp S, Grosu AL. Practical integration of [18F]-FDG-PET and PET-CT in the planning of radiotherapy for non-small cell lung cancer (NSCLC): the technical basis, ICRU-target volumes, problems, perspectives. Radiother Oncol 2006;81:209-25.

51. Nestle U, Schaefer-Schuler A, Kremp S, et al. Target volume definition for 18F-FDG PET-positive lymph nodes in radiotherapy of patients with non-small cell lung cancer. Eur J Nucl Med Mol Imaging 2007; 34:453-62.

52. Nowak B, Di Martino E, Jänicke $S$, et al. Diagnostic evaluation of malignant head and neck cancer by F-18-FDG PET compared to CT/MRI. Nuklearmedizin 1999;38:312-8

53. Nuutinen J, Sonninen $P$, Lehikoinen $P$, et al. Radiotherapy treatment planning and long-term follow-up with $[(11) \mathrm{C}]$ methionine PET in patients with low-grade astrocytoma. Int J Radiat Oncol Biol Phys 2000;48:43-52.

54. Ogawa T, Shishido F, Kanno I, et al. Cerebral glioma: evaluation with methionine PET. Radiology 1993;186:45-53.

55. Paskeviciute B, Bölling T, Brinkmann M, et al. Impact of (18)F-FDG-PET/CT on staging and irradiation of patients with locally advanced rectal cancer. Strahlenther Onkol 2009;185:260-5.

56. Paulino AC, Koshy M, Howell R, et al. Comparison of CT and FDG-PET-defined gross tumor volume in intensity-modulated radiotherapy for head-and-neck cancer. Int J Radiat Oncol Biol Phys 2005;61:1385-92.

57. Paulsen F, Scheiderbauer J, Eschmann SM, et al. First experiences of radiation treatment planning with PET/CT. Strahlenther Onkol 2006;182:369-75.

58. Räsänen JV, Sihvo EI, Knuuti MJ, et al. Prospective analysis of accuracy of PET, CT and EUS in staging of adenocarcinoma of the esophagus and gastroesophageal cancer. Ann Surg Oncol 2003;10:954-60.

59. Rickhey M, Koelbl 0, Eilles C, Bogner L. A biologically adapted dose-escalation approach, demonstrated for 18F-FET-PET in brain tumors. Strahlenther Onkol 2008;184:536-42.

60. Rutten I, Cabay JE, Withofs N, et al. PET/CT of skull base meningiomas using 2-18F-fluoro-L-tyrosine: initial report. J Nucl Med 2007;48:720-5.

61. Schaefer A, Kremp S, Hellwig D, et al. A contrast-oriented algorithm for FDG-PET-based delineation of tumour volumes for the radiotherapy of lung cancer: derivation from phantom measurements and validation in patient data. Eur J Nucl Med Mol Imaging 2008;35:1989-99.

62. Schinagl DA, Hoffmann AL, Vogel WV, et al. Can FDG-PET assist in radiotherapy target volume definition of metastatic lymph nodes in head-and-neck cancer? Radiother Oncol 2009;91:95-100.

63. Schot BW, Zijlstra JM, Sluiter WJ, et al. Early FDG-PET assessment in combination with clinical risk scores determines prognosis in recurring lymphoma. Blood 2007;109:486-91.

64. Senan S, De Ruysscher D, Giraud P, et al. Radiotherapy Group of European Organization for Research and Treatment of Cancer. Literature-based recommendations for treatment planning and execution for high-precision radiotherapy in lung cancer. Radiother Oncol 2004;71:139-46.

65. Solberg TD, Agazaryan N, Goss BW, et al. A feasibility study of 18F-fluorodeoxyglucose positron emission tomography targeting and simultaneous integrated boost for intensity-modulated radiosurgery and radiotherapy. $\mathrm{J}$ Neurosurg 2004;101:Suppl 3:381-9.

66. Steenbakkers RJ, Duppen JC, Fitton I, et al. Reduction of observer variation using matched CT-PET for lung cancer delineation: a three-dimensional analysis. Int J Radiat Oncol Biol Phys 2006;64:435-48.

67. Stroom J, Blaauwgeers H, van Baardwijk A, et al. Feasibility of pathologycorrelated lung imaging for accurate target definition of lung tumors. Int $\mathrm{J}$ Radiat Oncol Biol Phys 2007;69:267-275.
68. Sura S, Greco C, Gelblum D, et al. (18)F-fluorodeoxyglucose positron emission tomography-based assessment of local failure patterns in non-small-cell lung cancer treated with definitive radiotherapy. Int J Radiat Oncol Biol Phys 2008;70:1397-402.

69. Tralins KS, Douglas JG, Stelzer KJ, et al. Volumetric analysis of 18F-FDG PET in glioblastoma multiforme: prognostic information and possible role in definition of target volumes in radiation dose escalation. Nucl Med 2002;43:1667-73.

70. van Baardwijk A, Bosmans G, Boersma L, et al. PET-CT-based auto-contouring in non-small-cell lung cancer correlates with pathology and reduces interobserver variability in the delineation of the primary tumor and involved nodal volumes. Int J Radiat Oncol Biol Phys 2007;68:771-8.

71. van Baardwijk A, Bosmans G, Boersma L, et al. Individualized radical radiotherapy of non-small-cell lung cancer based on normal tissue dose constraints: a feasibility study. Int $\mathrm{J}$ Radiat Oncol Biol Phys 2008;71: 1394-401.

72. van Der Wel A, Nijsten S, Hochstenbag M, et al. Increased therapeutic ratio by $18 F D G-P E T-C T$ planning in patients with clinical CT stage N2/N3 M0 non-small cell lung cancer (NSCLC): a modelling study. Int J Radiat Oncol Biol Phys 2005;61:648-54.

73. Van Laere K, Ceyssens S, Van Calenbergh F, et al. Direct comparison of 18F-FDG and 11C-methionine PET in suspected recurrence of glioma: sensitivity, inter-observer variability and prognostic value. Eur J Nucl Med Mol Imaging 2005;32:39-51.

74. van Loon J, De Ruysscher D, Wanders R, et al. Selective nodal irradiation on basis of 18FDG-PET scans in limited disease small cell lung cancer: a phase II trial. Int J Radiat Oncol Biol Phys 2010;77:329-36.

75. van Tinteren H, Hoekstra OS, Smit EF, et al. Effectiveness of positron emission tomography in the preoperative assessment of patients with suspected non-small-cell lung cancer: the PLUS multicentre randomised trial. Lancet 2002;359:1388-93.

76. van Westreenen $\mathrm{HL}$, Westerterp M, Sloof GW, et al. Limited additional value of positron emission tomography in staging oesophageal cancer. $\mathrm{Br} \mathrm{J}$ Surg 2007;94:1515-20.

77. Vliegen RF, Beets-Tan RG, Vanhauten B, et al. Can an FDG-PET/CT predict tumor clearance of the mesorectal fascia after preoperative chemoradiation of locally advanced rectal cancer? Strahlenther Onkol 2008;184:457-64.

78. Vrieze 0, Haustermans K, De Wever W, et al. Is there a role for FGD-PET in radiotherapy planning in esophageal carcinoma? Radiother Oncol 2004;73:269-75.

79. Weber DC, Zilli T, Buchegger F, et al. [(18)]fluroroethyltyrosine-positron emission tomography-guided radiotherapy for high grade glioma. Radiat Oncol 2008;3:44.

80. Wright JD, Dehdashti F, Herzog TJ, et al. Preoperative lymph node staging of early-stage cervical carcinoma by [18F]-fluoro-2-deoxy-D-glucose-positron emission tomography. Cancer 2005;104:2484-91.

81. Yahalom J. Transformation in the use of radiation therapy of Hodgkin lymphoma: new concepts and indications lead to modern field design and are assisted by PET imaging and intensity modulated radiation therapy (IMRT). Eur J Haematol 2005;66:Suppl:90-7.

82. Zijlstra JM, Lindauer-van der Werf G, Hoekstra OS, et al. 18F-fluoro-deoxyglucose positron emission tomography for post-treatment evaluation of malignant lymphoma: a systematic review. Haematologica 2006; 91:522-9.

\author{
Address for Correspondence \\ PD Dr. Dr. Guido Lammering \\ MAASTRO Clinic \\ Postbus 1345 \\ 6201 BH Maastricht \\ The Netherlands \\ Phone (+31/88) 4455-600, Fax -773 \\ e-mail:guido.lammering@maastro.nl
}

